\title{
Exploring nursing student and faculty perceptions of incivility in the online learning environment
}

\author{
Jeanette McNeill *' Kathleen Dunemn, Katrina S. Einhellig, Lory Clukey \\ School of Nursing, University of Northern Colorado, Greeley, Colorado, United States
}

Received: October 12, 2016

Accepted: December 8, $2016 \quad$ Online Published: December 21, 2016

DOI: $10.5430 /$ jnep.v7n5p45

URL: http://dx.doi.org/10.5430/jnep.v7n5p45

\begin{abstract}
Objective: The purpose of the study was to explore student and faculty perspectives regarding what constitutes incivility in the online learning environment (OLE). Online learning is increasingly prevalent in nursing education. Scant research describes characteristics of OLEs contributing to, or inhibiting, learning or affecting civility among learners/faculty. Educators must effectively manage uncivil behavior to reduce incivility in learning and work environments. Attribution theory is helpful in examining issues related to incivility.

Methods and Results: Faculty $(n=34)$ and students $(n=44)$ reported perceptions of what constitutes incivility via an online survey, the Incivility in the Online Learning Environment (IOLE), an instrument described by Clark and colleagues. The groups reported somewhat different perceptions of the extent of incivility experienced but agreed on identification of uncivil behaviors. Both groups agreed that rude comments and name calling were definitely uncivil, however, several areas of disagreement existed between faculty and student groups as to other types of behaviors. For example, lack of timely feedback on assignments and an unclear syllabus were seen as incivility by students. High internal consistency (Cronbach's alpha of .98 on the faculty scale, and .96 on the student scale) was obtained for the IOLE in this sample. Qualitative comments regarding suggested ways to promote civility were similar from both groups, including role modeling and penalizing incivility; students emphasize the need for clearly stated course requirements.

Conclusions: Best practices are essential for developing/delivering online courses and in orienting faculty and students regarding expectations for professional behavior online. Faculty development should focus on using best practices to ensure online courses incorporate essential components enabling accessibility and efficiency for students navigating through them. Attention to this unique and increasingly typical learning environment is essential to the goal of prevention of incivility in both learning environments and subsequently in workplaces.
\end{abstract}

Key Words: Incivility, Nursing education, Online learning, Faculty student communication

\section{INTRODUCTION}

Online learning is an increasingly common experience for all students, involving about $1 / 3$ of all college students. ${ }^{[1]}$ Additionally, academic leaders indicated that almost $70 \%$ foresee online learning as critical to their long term strategy. ${ }^{[1]}$ This trend is certainly occurring in nursing education as well. However, there has been little research regarding the characteristics of the online learning environment that contribute to, or inhibit, learning or their influence on civility in the learning environment. Very few studies regarding the online nursing education environment have been reported, however, other authors have documented the occurrence of

*Correspondence: Jeanette McNeill; Email: jeanette.mcneill@unco.edu; Address: School of Nursing, University of Northern Colorado, Campus Box 125, Greeley, Colorado, United States. 
incivility in traditional learning environments. ${ }^{[2]}$ Shaeffer ${ }^{[3]}$ noted that consequences of incivility for nursing include the potential for academic incivility to "contribute to bullying in the workplace... and attrition..." (p. 178). This study aimed to examine the issue of incivility, its reported incidence and characteristics, from the student and faculty perspective, in the online learning environment in nursing education.

\subsection{Background and significance}

Clark et al. ${ }^{[4]}$ studied 212 nursing faculty $(\mathrm{n}=20)$ and students $(n=192)$ regarding reported lack of civility in online courses, using an investigator developed instrument, the Incivility in Online Learning Environment (IOLE) survey. Clark $^{[5]}$ defines incivility as, “. . . any rude or disruptive behavior that results in psychological or physiological distress for the people involved..." (p. 150). Clark et al. ${ }^{[4]}$ found that incivility was reported by both faculty and students to be a mild to moderate problem; several highly rated uncivil behaviors identified by students and faculty were 1) name calling, 2) making belittling comments about a faculty member, 3) making racial, ethnic, sexual or religious slurs, and 4) criticizing non-traditional cultures. Additionally, students reported uncivil faculty behaviors including faculty making comments that were personally attacking, or unexpected changes in course assignments. In contrast, faculty behaviors can convey caring, such as Sitzman's ${ }^{[6]}$ findings on a survey of $122 \mathrm{BSN}$ students revealing that students characterize effective online faculty teaching behaviors, such as providing clear directions for online participation and assignments, as a caring behavior which contributes to students' success in the course.

Crosslin and Golman ${ }^{[7]}$ noted the incidence of cyberbullying in college students, but emphasized that students admit rarely reporting such activities. Clark et al. ${ }^{[8]}$ urge that creation of a positive learning environment is crucial to countering the potential for anonymity and lack of face-to-face contact which can enable a hostile learning environment.

\subsection{Purpose and goals of the project}

The purpose of the project was to assess the occurrence and characteristics of incivility in the online learning environment (OLE) from both the faculty and the student perspective. As in many settings, the Rocky Mountain region School of Nursing has expanded its online course offerings for graduate and undergraduate courses; thus, it is essential to understand incivility in the online setting in order to ensure quality and student success in these programs. The results of this project guided faculty development to ensure faculty competencies related to civility in the online learning environment as well as improved student orientation to online course delivery.
These program evaluation measures are necessary in order to improve program and course delivery. Specifically, the project sought to examine:

(1) The extent that nursing faculty and students perceive incivility as a concern in the OLE of courses in the School of Nursing.

(2) Behaviors that are considered to be disrespectful or disruptive to learning from the perspective of nursing faculty and students.

(3) Student and faculty characteristics associated with incivility in the OLE.

\subsection{Conceptual framework}

The conceptual framework used to guide this research is based on the Attribution Theory originally introduced by Heider. ${ }^{[9]}$ This theory focused on how the perceiver uses information to arrive at explanations for the behavior of other people as well as his/her own behavior. ${ }^{[9]}$ Based on the idea that incivility is founded on the perceptions of the receiver of communication, this theory is appropriate for describing how individuals attempt to understand a behavior or action. Heider ${ }^{[9]}$ developed this theory in an attempt to understand why an event occurred so that subsequent events could be predicted. Hoffman ${ }^{[10]}$ used this theory to describe the differences between perceptions of student and faculty incivility across various types of nursing programs. An aspect of Attribution Theory ${ }^{[9]}$ that is particularly poignant within Hoffman's study is that Heider proposed the concept of Fundamental Attribution Error; this is the idea that when an individual assesses another person's behaviors, that they typically overestimate the influence of personal factors on the situation and underestimate the influence of situation factors. This is potentially an issue when faculty or students perceive incivility in the online learning environment. The incivility is potentially based on a myriad of factors, and it may be that very little has to do with the individual perceived as being uncivil.

\subsection{Review of literature}

\subsubsection{Incivility in the nursing classroom}

Historically, research on incivility in nursing education ${ }^{[2]}$ has attempted to understand how students and faculty perceive uncivil behaviors and the impact of these activities on the learning environment, primarily in the classroom. Studies have described the phenomenon of incivility from the student's unique perspective. Clark ${ }^{[2]}$ began the exploration of student perceptions' of incivility and detailed students' experiences with belittling comments by faculty as well as the idea they were being treated unfairly; these experiences led to feelings of powerlessness and anger. Students also perceive that negative interactions with nursing faculty actually 
contribute to incivility and these behaviors justify students acting uncivilly as well. ${ }^{[11]}$ Balko $^{[12]}$ specifically looked at the barriers facing registered nurses as they prepared to return to academia and how past memories of incivility within their nursing programs affected their current progression in the program.

\subsubsection{Faculty and student perceptions on incivility}

Research has also evaluated faculty perceptions' of student incivility ${ }^{[13]}$ and how this impacts their role as nurse educators. Luparell ${ }^{[13]}$ discussed how uncivil encounters with students affected nursing faculty, both physically and emotionally. The student behaviors were described at varying degrees of incivility, from mild to severely aggressive, but the consequences led to injury to faculty self-esteem, loss of sleep, and diminished confidence in teaching abilities. Some faculty felt this behavior caused irreparable damage and chose to leave the profession as a result of these student interactions. $^{[13]}$

Scrutiny of incivility in nursing education has also prompted the evaluation of perceptions of both students and nurse educators using the same scale, ${ }^{[14]}$ the Incivility in Nursing Education (INE) survey. Clark ${ }^{[14]}$ sought to develop a conceptual model that addresses a myriad of factors such as stress, ineffective communication, and personal attitudes, which all contribute to incivility in nursing education. Although a majority of both nurse educators and students believe that incivility is at least a minor problem in nursing education, there are considerable differences in the behaviors each group constitutes as an uncivil act. Clark determined that more research is needed to determine the impact of incivility on the learning environment, the students, and faculty.

\subsubsection{Incivility in online nursing education courses}

The increased use of the online venue in nursing education has created some unique benefits as well as challenges ${ }^{[8]}$ for both nurse educators and students. Although research ${ }^{[8]}$ has demonstrated ample benefits to online learning such as increased flexibility, convenience, and the opportunity for self-paced learning, there are some drawbacks as well. Challenges discussed by Clark et al. ${ }^{[8]}$ include faculty concerns such as the time-consuming nature of online classes and anonymity encouraging rude behavior, as well as students' negative perceptions regarding lack of faculty clarity and objectivity and excessive group work. The Incivility in Online Learning Environment (IOLE) Survey created by Clark et al. ${ }^{[4]}$ provides a descriptive tool that allows for measurement of faculty and student perceptions of uncivil behaviors as well as the perceived frequency of behaviors. This tool has excellent inter-item reliability as well as internal consistency (.98 for faculty and .96 for students). Rieck and Crouch ${ }^{[15]}$

Published by Sciedu Press also studied the issue of civility in online nursing programs, focusing on the students' perceptions of "connectiveness" and creating a community of learning. Students suggested that addressing the negative behaviors helped to diminish incivility in the online venue and proposed that netiquette guidelines are instrumental in providing for a positive learning environment. ${ }^{[15]}$

\subsubsection{Cyberbullying}

Cyberbullying is another concept linked with the electronic learning environment and social media. This form of incivility occurs through actions such as posting rumors, gossiping, or posting materials that demean or embarrass others. ${ }^{[8]}$ Crosslin and Golman ${ }^{[7]}$ report the incidence of cyberbullying in college students as ranging from $8 \%-21 \%$, but note that students surveyed indicate that they often fail to report instances of cyberbullying due to a perception that as adults, they should be able to handle it. In their analysis, these researchers noted students' belief that cyber bullying often had to do with retaliation or relationship difficulties. Research by Smith, Minor and Brashen ${ }^{[16]}$ addressed the overall incidence of cyberbullying in higher education and the lack of research regarding this issue within this particular population of students. Their recommendations are for institutions of higher learning to specifically address cyberbullying within academic policies to ensure that protection was provided for both students and faculty, and that faculty training was essential to ensure that faculty could readily recognize instances of cyberbullying and address them in an expeditious manner to minimize further behaviors. ${ }^{[16]}$

\subsubsection{Strategies to address incivility}

Research has also focused on the potential strategies that exist to address incivility in nursing education. ${ }^{[5]}$ Much of this research focuses on civility within the classroom or clinical setting. Based on the researcher's extensive background with this topic, Clark ${ }^{[5]}$ created a field guide for faculty to prepare them for the existence of incivility within nursing courses and provides several ready-to-use strategies for preventing and effectively dealing with the existence of student incivility. Jenkins, Kerber, and Woith ${ }^{[17]}$ studied one particular intervention, a journal club focused on civility in nursing, in order to build social capital and civility among nursing students. In their exploratory, mixed-methods design, they focused on changing the attitudes and behaviors of students as they prepared to enter professional practice. They concluded that targeted strategies aimed at eliminating incivility resulted in positive change in the professional demeanor and actions of nursing students. ${ }^{[17]}$ Following their participation, students refused to engage in uncivil behaviors, they supported their peers and were more likely to help others in the clinical setting. 


\subsubsection{Best practices in the online learning environment}

Literature regarding best practices in online education focus on several strategies for creating a positive learning environment for both faculty and students. ${ }^{[5]}$ This is done through faculty role-modeling the type of communication they expect within online courses as well as immediate feedback when there is a perception of incivility. ${ }^{[5]}$ Sitzman and Watson ${ }^{[18]}$ also discuss the timeliness of interactions as vastly important. Their recommendation is to respond to instructor and peer messages within 24 hours to ensure communication remains fluid and reciprocal. It is also important to institute learning strategies that emphasize a cooperative environment and that all parties feel respected and appreciated. ${ }^{[5]}$ Focus has also been paid to the importance of online asynchronous discussion boards and the value of this online pedagogical strategy for learning new concepts and sharing anecdotal experiences. ${ }^{[19]}$ Baker discusses the faculty role as one of promoting cohesiveness, preserving presence, and continuous communication while faculty and students engage in discussion boards. ${ }^{[19]}$ Plante and Asselin ${ }^{[20]}$ also note the importance of timely communication as essential to positive online environments. Further, these authors recommend that sense of social presence can be promoted by having students post photographs of themselves, as well as encouraging interactions through teamwork on assignments.

\subsubsection{Impact of incivility in nursing education on the prac- tice environment}

Finally, when discussing the issue of incivility in online nursing education, it is essential that research investigates the potential that incivility endured while in the learning setting has a potential impact on graduates as they enter the professional environment. Researchers ${ }^{[21]}$ have worked to understand the incidence of incivility within nursing education and the possible implications for graduates entering professional practice. Del Prato ${ }^{[21]}$ sought to understand the experience of nursing students when faced with faculty incivility and how demeaning experiences and rigid expectations affected them as they transitioned toward practice. The goal was to understand the impact that faculty play on the professional role development of student nurses. Hunta and Marini ${ }^{[22]}$ also evaluated the continuum of bullying behaviors observed by clinical nursing teachers and emphasized the role of nurse educators in helping students to identify incivility within the practice environment and the need for programs to target and address incivility in order to prepare nurses who are able to foster a civil workplace. Elmore ${ }^{[23]}$ created a Toolkit of Resources to Address Incivility in Nursing (TRAIN). The emphasis of this research was the review and application of an evidenced-based toolkit for use by practicing nurses to learn to manage incivility in the practice setting provid- ing a positive impact on nurses, patients, organizations, and decreasing nursing turn-over rates.

The incidence of incivility within nursing education, specifically within the online learning environment, has been studied in order to determine the incidence and implications of such behaviors. ${ }^{[2,4,5,7,10,12]}$ There remains a dearth of evidence regarding incivility within higher education and how such experiences impact the socialization of professional nurses. Further research must focus on the enhanced development of faculty regarding the identification and management of incivility within online nursing courses and the preparation of nurses who can enter professional practice prepared to cultivate positive healthcare work environments.

\section{METHODS}

\subsection{Institutional review}

Approval was received from the Institutional Review Board for the Ethical Conduct of Research Committee at the University where the study was conducted. All participants were ensured anonymity and had a choice to participate or not to participate. Returning a completed survey (via online) was considered consent for participation in this study. Data were stored securely on a password protected server.

\subsection{Survey instrument}

Permission to use the Online Learning Environment Survey was obtained from the original authors. ${ }^{[4]}$ Requests to participate and surveys were sent via email to all nursing students enrolled in online (or hybrid) nursing courses and nursing faculty teaching full time and adjunct (part-time) at a Rocky Mountain region university school of nursing between October 2015 and February 2016. Graduate (Master's, DNP and $\mathrm{PhD}$ ) and undergraduate (RN-SBSN) courses that were offered either online or hybrid ( $>25-80$ online) between Fall, 2015 and Spring, 2016 were selected and faculty teaching those courses, and students enrolled in those courses were invited to participate. Responses from faculty and students were independent of each other, and no attempt was made to correlate faculty and student responses.

Participants completed the Online Learning Environment (IOLE) survey developed by Clark et al. ${ }^{[4]}$ The IOLE elicits reported faculty and student uncivil behaviors, including the reported frequency of those behaviors, as well as respondents' open ended comments about on-line learning. Participants also had the opportunity to suggest ways to promote civility in on-line environments. The IOLE's validity and reliability has been reported in several studies demonstrating content validity and internal consistencies of $>.96 .^{[4]}$

The tool consists of 28 items and collects both quantitative 
and qualitative data. Several demographic items are included and are somewhat customizable for a particular setting based on the licensure agreement. This section includes eight general questions followed by six student specific and seven faculty specific questions including type of program, rank (for faculty), expertise in teaching online courses and number of courses taught (faculty) or courses taken (student). ${ }^{[4]}$ The main questions of the survey use a Likert Scale to score items and are similar for faculty and students. Nineteen student behaviors are presented which the respondent rates regarding the level of disruption to learning, and correspondingly, how often the behavior has been witnessed or experienced in the past year. The behaviors include several variations of rude comments-attacking, threatening and belittling - as well as slurs, breaches of confidentiality, cheating and group work issues. $^{[4]}$ A similar question rating 24 faculty behaviors is presented using the same Likert scale and adding faculty specific behaviors related to clarity of syllabus and assignment instructions, quality and timeliness of feedback. ${ }^{[4]}$ Two additional Likert scale items query how problematic the respondent considers incivility in the OLE, and who (faculty or student) is more likely to engage in such behaviors. ${ }^{[4]}$ The survey ends with three open ended questions asking the participant for their comments regarding the challenges and advantages in online learning and ways of promoting civility in online courses. ${ }^{[4]}$

\subsection{Data analysis}

The data were analyzed in two stages. The first stage was analysis and computation of the descriptive statistics and the distribution of the data for each variable. The second stage of the data analysis was an exploration of the associations among selected study variables. Data were analyzed using the Statistical Package for the Social Sciences (SPSS) computer programs. ${ }^{[24]}$ A Type I error of five percent was used for all tests of statistical significance. Data distributions were inspected for the presence of outliers and excessive nonnormality. Missing data was imputed following guidelines in the respective scale manuals. Parametric or nonparametric statistical methods were used based on standard assumptions. ${ }^{[25]}$ Qualitative data was summarized. The research team reached consensus on the information obtained through the qualitative findings.

\section{Results}

\subsection{Descriptive summary of the sample}

The study population totaled 76 (faculty $=32$; students $=44$ ). Student respondents included 40 women (90.9\%), and 4 men (9.1\%). Among the faculty respondents, 29 (90.6\%) were women and $3(9.4 \%)$ were men. For both faculty and students the majority of the respondents identified as white/Caucasian

Published by Sciedu Press
(Students $=87.6 \% ;$ Faculty $=91.2 \%$ ). Faculty ranged in age from 28 - 64 years (mean, 48.97 [SD, 10.78] years). Questions regarding faculty expertise in teaching and online teaching noted a range of teaching experience (1 year to 37 years (mean 10.82 [SD, 9.13] years), and the number of online courses taught ranged from 1 to 20 (mean 6.62 [SD, 6.55] classes. Thirty-four percent of faculty members indicated high or very high expertise in online instruction while nearly $60 \%$ of the faculty reported average or less than average skill in online teaching. Students' ages ranged from 27 - 61 years (mean 40.14 [SD, 9.43] years), and the number of online courses taken throughout their education ranged from 2 to 20 (mean 11.17 [SD, 4.80]). Although the students were enrolled in several nursing programs, the majority of the respondents were enrolled in doctoral programs (DNP and $\mathrm{PhD}$ ) with approximately $30 \%$ in the RN-BSN program.

Table 1. Descriptive summary of sample

\begin{tabular}{|c|c|c|c|c|}
\hline \multirow{2}{*}{ Variables } & \multicolumn{2}{|c|}{ Faculty $(n=32)$} & \multicolumn{2}{|c|}{ Students $(n=44)$} \\
\hline & $\mathbf{n}$ & $\%$ & $\mathbf{n}$ & $\%$ \\
\hline \multicolumn{5}{|l|}{ Gender } \\
\hline Male & 3 & $9.4 \%$ & 4 & $9.1 \%$ \\
\hline Female & 29 & $90.6 \%$ & 40 & $90.9 \%$ \\
\hline \multicolumn{5}{|l|}{ Ethnic/racial background } \\
\hline Asian & 1 & $3.1 \%$ & 1 & $2.2 \%$ \\
\hline Black/African American & 1 & $3.1 \%$ & 1 & $2.2 \%$ \\
\hline Hispanic (non-Latino) & 1 & $3.1 \%$ & 2 & $4.4 \%$ \\
\hline White/Caucasian & 28 & $87.6 \%$ & 42 & $91.2 \%$ \\
\hline Other & 1 & $3.1 \%$ & 0 & $0.0 \%$ \\
\hline
\end{tabular}

Cronbach alpha inter-item coefficients indicate the extent to which individual items related to other items on this survey. A Cronbach $\alpha$ estimate of .976 indicated high inter-item reliability. Internal consistency reliability was computed on the scales surveying faculty and student incivility, indicating Cronbach $\alpha$ 's of .975 (faculty scale) and .956 (student scale). These Cronbach's $\alpha$ represent high internal consistency of scale items. These results are consistent with Cronbach's $\alpha$ results reported by Clark et al. ${ }^{[4]}$

Study respondents were asked to rate the extent to which incivility was a problem in the OLE. Overall, most faculty (n $=26,86.7 \%)$ noted incivility as a mild to moderate problem, while less than half of the students $(n=18,42.9 \%)$ found incivility to be a mild to moderate problem; over half of the students $(\mathrm{n}=22,52.3 \%)$ and two faculty members, or $6.7 \%$, responded that there was no problem regarding incivility. Only one faculty member and one student reported that incivility in the OLE was serious problem.

Finally, respondents commented on the likelihood of engaging in behavior considered uncivil in the OLE. Most faculty 
$(60 \% ; \mathrm{n}=18)$ and students $(54.8 \% ; \mathrm{n}=23)$ responded that students were more likely to engage in behavior considered uncivil. A small percentage of faculty (3.3\%) and students $(4.7 \%)$ thought that faculty members were slightly more likely to commit an uncivil behavior while no faculty or student respondents indicated that faculty members were more likely to engage in uncivil behavior. Twenty percent $(n=6)$ of the faculty and $14.3 \%(n=6)$ of the students responded that there was an equal likelihood that students or faculty could demonstrate incivility in online environments.

\subsection{Uncivil student behavior}

One of the primary goals of the study was to ascertain student and faculty behaviors that respondents reported as uncivil and how frequently they occurred. Table 2 displays categories of behaviors that both faculty and students agree are uncivil, whether committed by faculty or students. The behaviors have been categorized into three groups: 1) general rudeness, such as attacking, belittling or racial/ethnic slurs which are identified as uncivil by at least $85 \%$ of students and faculty; 2) inappropriate or inequitable group work, identified by over $78 \%$ of students and faculty, and 3) cheating, agreed upon by over $75 \%$ of both groups (see Table 2). There was a statistically significant association between the faculty and student responses for this group of questions indicating high agreement regarding student behaviors considered uncivil $(r$ $(18)=.814, p=.000)$.

While the actual experience (in the last 12 months) of uncivil behaviors in the IOLE reported by faculty and students was overall relatively low (ranging from $2.3 \%$ to $71 \%$ over the last 12 months depending on the behavior), the leading ones identified by faculty as occurring within the last year had to do with students submitting late assignments (71\%); insufficient or poor quality discussion posts which do not add meaning to the online discussion (55\%); and failing to fulfill group responsibilities (41.9\%). Students reported similar uncivil behaviors from other students but with slightly different frequencies, for example, failing to complete assignments in a timely manner was identified as uncivil by only $42 \%$ of students vs. $71 \%$ of faculty. Both faculty and students most frequently identified uncivil student behaviors to be in the general category of rude comments, and there was a high correlation between the faculty and student responses for this group of questions $[r(18)=.954, p=.000)]$.

Table 2. Perceived Student Incivility

\begin{tabular}{lll}
\hline Uncivil Student Behavior & Faculty Report (Usually/Always) & Student Report (Usually/Always) \\
\hline General Rude Comments & & \\
Attacking & $>85 \%$ agreement & $>85 \%$ agreement \\
Belittling & & \\
Racial/ethnic slurs & $>78 \%$ & $>86 \%$ \\
Inappropriate or inequitable group work & $>81 \%$ & $>86 \%$ \\
Cheating & $>81 \%$ \\
\hline
\end{tabular}

As shown in Table 2, displayed is the degree to which faculty and students perceived the category of student behaviors as always or usually uncivil.

\subsection{Uncivil faculty behavior}

Faculty behaviors that respondents reported as uncivil were similarly categorized by level of agreement that the behavior was always or usually uncivil. Three general categories were noted, that is, general rudeness, unanticipated changes in course requirements, and lack of, or untimely, feedback (see Table 3). These categories of behaviors were agreed upon by over $75 \%$ of students. There was a high correlation between the faculty and student responses for this faculty behaviors considered to be uncivil $[r(22)=.631, p=.002)]$.

Similar to the frequency of uncivil student behavior, the reported incidence was relatively low (ranging from $0 \%$ to $53 \%$ over the last 12 months depending on the behavior). How- ever, some faculty behavior was reported as frequent-for example, $50 \%$ of students noted that they had experienced unclear expectations about assignments, and lack of timely grading or response to student posts. Additionally, 27\% of the students complained about faculty assigning the same grade to all students in a group despite unequal contributions and lack of useful feedback on graded assignments. Overall, there was a high correlation between the faculty and student ratings for this group of responses $[r(20)=.834, p=.000)]$, although there were some differences in specific ratings.

As shown in Table 3, displayed is the degree to which faculty and students perceived certain categories of faculty behaviors as usually or always uncivil.

\subsection{Qualitative data}

Three open ended questions produced qualitative data regarding the online learning environment and incivility. The 
questions were: (1) the greatest challenge I have with online learning is...; (2) To me, the greatest advantage of online learning is...; (3) the most effective way to promote civility in online learning is to... For the purposes of this study, only question three regarding ways of promoting civility was examined via content analysis.

Table 3. Perceived Uncivil Faculty Behaviors

\begin{tabular}{lll}
\hline Uncivil Faculty Behavior & Faculty Report (Usually/Always) & Student Report (Usually/Always) \\
\hline General Rude Comments & & \\
$\quad$ Attacking & $>90 \%$ agreement & $>90 \%$ agreement \\
Belittling & & \\
Racial/ethnic slurs & & \\
Unanticipated Changes in Course Requirements & & $>75 \%$ agreement \\
Assignments & $>75 \%$ agreement & \\
Due dates & & $>95 \%$ \\
$\quad$ Unclear instructions & & \\
Feedback & $>73 \%$ & \\
$\quad$ Timeliness & & \\
Lack of useful comments & & \\
\hline
\end{tabular}

Suggestions for promoting civility online were similar for both groups. Important factors were modeling civil behavior (52\% of faculty and $29 \%$ of student comments) and establishing a strong online presence in the class with ongoing monitoring of behavior. A need for establishing rules and clear guidance and expectations for online communication was emphasized (48\% of faculty and $46 \%$ of student comments). Both groups urged an immediate response to disruptive behavior, zero tolerance of incivility, and an off-line reprimand. While these were responses to a survey, the qualitative data provides corroboration for the quantitative findings, and information that will be used to guide a future research study.

\section{Discussion}

In this study, a majority of the faculty and almost half of the students report incivility in the OLE to be problematic. This leaves one to question if there might be a directional component to uncivil behavior in an online environment. Further research in this area is needed. Students may feel more empowered and less inhibited when interacting with faculty in an online class. It might be that online environments equalize the power differential? Attribution theory ${ }^{[9]}$ may explain both the types of behaviors, both faculty and student, considered to be uncivil, as well as the differences between perceptions of students and faculty as to what is considered uncivil. While the qualitative data did not specifically describe uncivil behaviors, responses to the third open ended question describe the converse, that is approaches to promoting civil interaction which correlate well with identified best practices in creating an effective online learning environment. Several areas of best practice to promote ci-

Published by Sciedu Press vility were supported by the data, both those identifying the most disruptive faculty and student behaviors, as well as the issues raised related to challenges in online learning that may contribute to incivility.

\subsection{Frequency and characteristics of uncivil behaviors}

A majority of the faculty and the students reported that students were more likely than faculty to engage in uncivil behavior in an OLE. Clark et al. ${ }^{[4]}$ report similarly that almost $40 \%$ of faculty and $20 \%$ of students believed that students were more likely to engage in uncivil behavior, however, a substantial number of faculty (17\%) and students (20\%) perceived that there is an equal possibility of uncivil behavior from the two groups. Further research into actual events experienced by faculty and students could shed light on the incidence and prevalence of uncivil behavior in the OLE with specific examples to elucidate definitional terms.

The results indicate statistically significant association in responses between the faculty and students regarding student behaviors reported to be uncivil and the reported frequency of identified behaviors. There was a high level of consistency regarding the identification of uncivil behaviors between faculty and students. Behaviors that were a direct affront were most frequently agreed upon. These included rude comments such as attacking, belittling, or making slurs, as well as negative comments about others (students or faculty), and cheating. Again, this is similar to the findings of Clark et al. ${ }^{[4]}$

Faculty and students perceived the following behaviors to be the most frequently occurring uncivil behaviors of students: lack of timely completion of assignments, posting 
online discussion board posts that failed to add substantively to the quality of the discussion, and lack of full participation in group work. These results highlight the potential importance of structured online orientations in assisting students to create realistic expectations regarding online classes which is consistent with best practices in creating a caring learning environment. ${ }^{[18]}$ Online orientations should include at minimum: guidelines for communicating effectively, a student code of conduct, and specific expectations regarding participation in online discussions as well as group projects

Additionally the results indicate a statistically significant association in responses between the faculty and students regarding faculty behaviors reported as uncivil, as well as the reported frequency of such behaviors. Faculty and students noted several behaviors indicating faculty incivility with faculty perceiving frequency of these behaviors to be higher than students did. Behaviors noted included: posting a vague syllabus or unclear expectations about assignments, lack of timeliness in posting grades or responding to student postings; these findings are consistent with those of Clark et al. in a sample of undergraduate students. ${ }^{[4]}$ This particular set of results emphasizes the need for faculty development related to online teaching. Especially for faculty with limited online teaching experience, development opportunities have the capacity to instruct faculty on various methods to create a positive online learning environment. Specific attention should focus on the ideals of role-modeling professional behaviors as well skills for conflict management. Sitzman ${ }^{[6]}$ expounds on this point linking faculty behaviors to the demonstration of caring in online course delivery. She found that behaviors perceived as conveying and sustaining a caring learning environment were ranked as extremely important by students. For example "posting clear instructions regarding schedules and due dates" [p. 173] was noted by $97 \%$ of respondents, and "responding to postings and emails within 48-72 hours" [p. 173] was noted by $82 \%$. Sitzman and Watson ${ }^{[18]}$ notes that conveying caring in online nursing education supports this core value for the profession. Students who have developed as professionals in a caring learning environment are more likely to apply caring behaviors to their patients, nurses, and colleagues. These nursing professionals will be prepared to avoid engaging in workplace incivility.

\subsection{Antecedents to uncivil behavior in the online envi- ronment}

In their comments, faculty reported a lack of connection to students as one of the disadvantages to online learning. This manifested itself as a perception of not being able to engage or motivate students and may contribute to incivility on the part of students, or lack of clarity on the part of faculty. Students, for example, perceived assignments as being vague. Faculty and students struggled with clarity in communicating and understanding course expectations. These findings corroborate Clark et al. ${ }^{[7]}$ where faculty and students commented on the difficulties of creating a sense of community without face to face communication among faculty and students to address issues and concerns, and create a "supportive teaching/learning environment" (p. 193).

Both faculty and students noted that online education "takes longer". This time challenge may contribute to uncivil behaviors. Students noted that they were delayed in being able to complete assignments due to late posting by other students. These factors related to time are evident in the quantitative responses. Faculty perceive time expectations from students to be unreasonable, while students feel they are not able to keep up because of the behavior of other students (delayed postings to which others are required to respond). Again, attribution theory ${ }^{[9]}$ may explain the characterization of such behavior to be due to personal, vs situational factors, and lead to an individual responding in an uncivil manner. ${ }^{[9]}$ Clark et al. ${ }^{[8]}$ reported similar faculty comments regarding time commitment, but do not note student comments about time commitment per se, although they do comment about the challenge of keeping up with due dates for posting assignments. These frustrations may also lead to incivil behavior, but further exploration of what is uncivil and what is simply inconvenient is needed regarding online course delivery. Time commitment and workload for online courses is identified as a problematic area for both students and faculty. Students and faculty have difficulty with the unpredictability of time needed for assignments, grading, and engagement in the course. Frustration with this issue may lead online course participants to feel disrespected, as if their time is not valuable. These frustrations of the online format may manifest themselves as incivility, related to Heider's attiribution theory. ${ }^{[9]}$

Although the results of this research endeavor do not demonstrate that incivility in the online learning environment is a severe problem within nursing education, at least in this setting, it is obvious that incivility does exist. As long as this type of unprofessional behavior is a realistic concern for students and nurse educators, interventions must be designed to ensure that all participants work toward a positive milieu. Carefully planned orientation for students and development for faculty provide an opportunity to socialize both to the online environment and create an atmosphere of collegiality and professionalism that can pervade the practice environment. 
4.3 Best practices in course design and delivery to reduce occurrence of incivility

In order to ensure the effectiveness of online learning environments in promoting learning, barriers such as the potential for incivility, must be addressed. Faculty development is needed to provide both structural (course organization, clarity regarding assignments and evaluation, etc.) and process (delivery of the components of the course such as course discussion, thoughtful and timely feedback on assignments, etc.) guidance to faculty as they teach online. These aspects of faculty development for online course delivery are consistent with best practices as identified by Baker ${ }^{[19]}$ and Sitzman and Watson. ${ }^{[18]}$ Student orientation as to the unique challenges and components of learning in the online environment must be carefully developed and provided for every online learner.

As reported by several authors, notably Sitzman ${ }^{[6]}$ and Sitzman and Watson, ${ }^{[18]}$ students perceived such careful orientation to their learning as caring, which they report conveys encouragement and is conducive to their success. A toolkit for faculty and student orientation to the rich learning opportunities in the OLE is needed and is currently in development in the Rocky Mountain university setting based on study results. For example, in the introduction to a course, faculty can make a clear statement that "gossiping" or "belittling" fellow colleagues, even outside of the online class, is not acceptable professional behavior and that it contributes to disenfranchising others. Students suggest that any form of incivility or cyberbullying be addressed immediately and off line. They also suggest that faculty role model appropriate communication. Again, faculty may be able to accomplish this with clear instructions about appropriate communication that is set forward at the beginning of the course. An explicit policy statement regarding consequences for uncivil behaviors should be provided. Consistency of faculty addressing concerns promptly and forcefully is imperative. A phone call to an offending student will allow direct communication and garner attention. Faculty typically have the ability to remove student comments from the OLE which needs to be done immediately with a reminder that rude and hurtful comments will not be tolerated.

Factors associated with timeliness and clear communication are perceived as important in an online environment. Faculty development can facilitate an anticipatory approach, for ex- ample, faculty can anticipate challenges related to students' complaints about changes to syllabus, and lack of timely interaction, and preempt those concerns with clear communication and feedback. Such approaches can help to bridge the perceptions of students and faculty regarding incivility. Specifically, faculty need to post timelines for grading assignments, availability for questions, and best ways to reach faculty for responses to questions; definitive information about availability, daily or every other day, and on weekends and holidays should be provided. Overall, faculty need to have an online presence that is identifiable.

\section{Conclusion}

Both faculty and students perceive that incivility exists in the online environment. There is a strong correlation between what faculty and students identify as uncivil behavior. The behaviors noted as uncivil leave one to question the need for a new definition of incivility in the online environment. More investigation into how incivility is perceived in an online course is needed. Faculty and students seem to have shared perceptions regarding the most egregious behaviors, but the more subtle behaviors, such as late grading or an unclear syllabus, need further examination. Some of the behaviors that have convergence with student and faculty perceptions of incivility appear to be related to clarity of communication and time. Do these challenges trigger truly uncivil behavior, or are they inconvenient and frustrating? Communicating regarding course and assignment expectations was noted as a problem by both students and faculty. Difficulty with feeling connected was a source of angst. The time commitment, timeliness of responses and grading of assignments, and expectations of response time were all noted as problematic.

There is strong agreement that personal comments that belittle others or "gossip" are considered inappropriate. What is not yet known are if there are specific elements of the online learning environment that heighten the potential for incivility. There remains the need for further research and more exploration of incivility in the online environment as nursing education moves to increasing use of technology and learning at a distance.

\section{Conflicts of InTERest Disclosure}

The authors declare that there is no conflict of interest.

\section{REFERENCES}

[1] Allen IE, Seaman J. Changing course: Ten years of tracking online education in the US. New York: Pearson Publishing; 2013.
[2] Clark C. Incivility in nursing education: Student perceptions of uncivil faculty behavior in the academic environment [dissertation]. [Boise (ID)]. University of Boise; 2006. 155 p. 
[3] Shaeffer A. The effects of incivility on nursing education. Open Journal of Nursing. 2013; 3: 178-181. https://doi.org/10.4236/ ojn. 2013.32023

[4] Clark C, Werth L, Ahten S. Cyber-bullying and incivility in an online learning environment, Part 1. Nurse Educator. 2012; 37(4): 150-156. PMid:22688872 https ://doi.org/10.1097/NNE.0b013e3182 5 a87e5

[5] Clark C. Faculty field guide for promoting student civility in the classroom. Nurse Educator. 2009; 34(5): 194-197. PMid:19726958 https ://doi.org/10.1097/NNE.0b013e3181b2b589

[6] Sitzman K. Student-preferred caring behaviors for online nursing education. Nursing Education Perspectives. 2010; 31(3): 171-178. PMid:20635622

[7] Crosslin, K, Golman M. "Maybe you don't want to face it" - College students' perspectives on cyberbullying". Computers in Human Behavior. 2014; 41: 14-20. https ://doi.org/10.1016/j.chb. 20 14.09 .007

[8] Clark C, Werth L, Ahten S. Cyber-bullying and incivility in an online learning environment, Part 2. Nurse Educator. 2012; 37(5): 192-197. PMid:22914274 https://doi.org/10.1097/NNE.0b013e3182 $62 \mathrm{eb} 2 \mathrm{~b}$

[9] Heider F. The psychology of interpersonal relations. New York, NY: Wiley; 1958

[10] Hoffman RL. Differences in student perceptions of student and faculty incivility among nursing program types: An application of attribution theory [dissertation]. [Indiana (PA)]: Indiana University of Pennsylvania; 2012. 269p.

[11] Altmiller G. Student perceptions of incivility in nursing education: implications for educators. Nursing Education Perspectives. 2012; 33(1): 15-20. https://doi.org/10.5480/1536-5026-3 3.1 .15

[12] Balko KA. Experiences of incivility \& ageism in currently enrolled RN to BS nursing students and their intent to quit [dissertation]. [Minneapolis (MN)]: Capella University; 2013. 152 p

[13] Luparell S. Critical incidents of incivility by nursing students: How uncivil encounters with students affect nursing faculty [dissertation]. [Lincoln (NA)]: University of Nebraska; 2003. 119 p.
[14] Clark C. Student voices on faculty incivility in nursing education: a conceptual model. Nursing Education Perspectives. 2008; 29(5): 284-289. PMid:18834058

[15] Rieck S, Crouch L. Connectiveness and civility in online learning. Nurse Education in Practice. 2007; 7(6): 425-432. PMid:17765016 https://doi.org/10.1016/j.nepr.2007.06.006

[16] Smith GS, Minor MA, Brashen HM. Cyberbullying in higher education: Implications and solutions. Journal of Educational Research and Practice. 2014; 4(1): 50-60.

[17] Jenkins SD, Kerber CS, Woith WM. An intervention to promote civility among nursing students. Nursing Education Perspectives. 2013; 34(2): 95-100. https://doi.org/10.5480/1536-5026-34.2. 95

[18] Sitzman K, Watson, J. Watson's caring in the digital world. New York, NY: Springer; 2017.

[19] Baker DL. Advancing best practices for asynchronous online discussion. Business Education Innovation Journal. 2013; 5(1): 11-20.

[20] Plante K, Asselin, ME. Best practices for creating social presence and caring behaviors online. Nursing Education Perspectives. 2014; 35(4): 219-223. https ://doi .org/10.5480/13-1094.1

[21] Del Prato D. Students' voices: The lived experience of faculty incivility as a barrier to professional formation in associate degree nursing education. Nurse Education Today. 2013; 33(3): 286-290. PMid:22726346 https : //doi.org/10.1016/j.nedt.2012.05 .030

[22] Hunta C, Marini ZA. Incivility in the practice environment: A perspective from clinical nursing teachers. Nurse Education in Practice. 2012; 12(6): 366-370. PMid:22634060 https://doi.org/10.1 016/j.nepr. 2012.05.001

[23] Elmore DO. Development of a toolkit of resources to address incivility in nursing (TRAIN) [dissertation]. [Minneapolis (MN)]: Walden University; 2014. 72 p.

[24] IBM Corp. Released 2012. IBM SPSS Statistics for Windows, Version 21.0. Armonk, NY: IBM Corp.

[25] Kellar SP, Kelvin E. Munro's statistical methods for health care research (6th ed.). Philadelphia, PA: Lippincott, Williams \& Wilkins; 2014. 